\title{
Combined impact of smoking and heavy alcohol use on cognitive decline in early old age: Whitehall II prospective cohort study
}

\author{
Gareth Hagger-Johnson, Séverine Sabia, Eric John Brunner, Martin Shipley, Martin Bobak, \\ Michael Marmot, Mika Kivimaki and Archana Singh-Manoux
}

\section{Background}

Identifying modifiable risk factors for cognitive decline may inform prevention of dementia.

\begin{abstract}
Aims
To examine the combined impact of cigarette smoking and heavy alcohol consumption on cognitive decline from midlife.
\end{abstract}

\section{Method}

Prospective cohort study (Whitehall II cohort) with three clinical examinations in 1997/99, 2002/04 and 2007/09.

Participants were 6473 adults (72\% men), mean age 55.76 years (s.d. $=6.02)$ in 1997/99. Four cognitive tests, assessed three times over 10 years, combined into a global $z$-score (mean 0, s.d. $=1$ ).

\section{Results}

Age-related decline in the global cognitive score was faster in individuals who were smoking heavy drinkers than in non-smoking moderate alcohol drinkers (reference group). The interaction term $(P=0.04)$ suggested that the combined effects of smoking and alcohol consumption were greater than their individual effects. Adjusting for age, gender, education and chronic diseases, 10-year decline in global cognition was -0.42 z-scores $(95 \% \mathrm{Cl}-0.45$ to -0.39$)$ for the reference group. In individuals who were heavy alcohol drinkers who also smoked the decline was $-0.57 \mathrm{z}$-scores $(95 \% \mathrm{Cl}-0.67$ to -0.48$) ; 36 \%$ faster than the reference group.

\section{Conclusions}

Individuals who were smokers who drank alcohol heavily had a $36 \%$ faster cognitive decline, equivalent to an ageeffect of 2 extra years over 10-year follow-up, compared with individuals who were non-smoking moderate drinkers.

\section{Declaration of interest}

None.
Cognitive decline refers to a wide continuum of changes in cognitive function across the life course, including both agerelated decline and pathological decline. ${ }^{1}$ Poor cognitive status, even in the absence of clinical dementia, is perhaps the single most disabling condition in old age. Dementia is a syndrome characterised by impairment of multiple cognitive capacities that are severe enough to interfere with daily functioning. It is often preceded by mild cognitive impairment, defined as 'cognitive impairment short of dementia' or as 'a transitional state between normal cognition and dementia. ${ }^{2}$ It is estimated that pathological changes that lead to dementia start as early as several decades before clinical diagnosis. ${ }^{3,4}$ An effective cure for dementia remains elusive and given high and rising treatment and care costs, knowledge about early modifiable risk factors may be important from a public health perspective. Importantly, unhealthy behaviours may accelerate cognitive decline and be amenable to low-cost intervention at a population level. ${ }^{5}$ In the UK, cigarette smoking and heavy alcohol consumption remain prevalent, including among older adults. ${ }^{6}$

Several studies have found an association between smoking and cognitive decline ${ }^{7-9}$ and dementia. ${ }^{8}$ Earlier studies apparently suggesting a protective effect of smoking ${ }^{10,11}$ were later attributed to selection bias. ${ }^{12}$ Evidence concerning alcohol use as a risk factor for cognitive decline and dementia is also mixed. There may be non-linear associations between alcohol and cognitive outcomes. For example, a meta-analysis found lower risk of dementia in people who were moderate (for example up to 14 units per week for women and up to 21 units per week for men) but not heavy drinkers compared with non-drinkers. ${ }^{13}$ Smoking and heavier alcohol consumption often co-occur ${ }^{14}$ and their combined effect on cognition may be larger than the sum of their individual effects. In combination they have been associated with greater risk of all-cause mortality in an occupational cohort in West Scotland ${ }^{15}$ and with aerodigestive cancer risk in a meta-analytic study. ${ }^{16}$ To date few studies have examined the combined effect of smoking and alcohol use on cognitive decline. In two early cross-sectional studies of community-dwelling older adults in the USA (age 60-84), one found no greater combined effect ${ }^{17}$ and the other found general cognitive function to be $6 \%$ lower among those who smoked and drank alcohol heavily compared with all other groups. ${ }^{18}$ An earlier study of older adults in the USA (age 65 and older) found no separate effects but did not test for a possible interaction. ${ }^{19}$ A later study in Finland found more frequent $(v$. never or infrequent) alcohol use in midlife was associated with better cognitive performance 21 years later (at age 65-79), which was stronger among non-smokers. ${ }^{20}$

The evidence from studies on older populations on the combined effect of alcohol and smoking on the risk of cognitive function, ${ }^{17,18,20}$ cognitive decline, ${ }^{19,21}$ or later Alzheimer's disease $^{12,22}$ is inconsistent. An added complication is that older smokers are a selected population. ${ }^{9}$ As cognitive decline is evident in midlife, ${ }^{3}$ the aim of our study was to examine whether cigarette smoking and alcohol consumption interact to accelerate cognitive decline in the transition from midlife to early old age.

\section{Method}

\section{Study population}

The Whitehall II cohort was established in 1985/88 among 10308 British civil servants. ${ }^{23}$ All civil servants aged 35-55 years in 20 London-based departments were invited to participate by letter, and $73 \%$ agreed $(67 \%$ men). Cognitive testing was introduced in $1997 / 99$ (the baseline for our analysis) during a clinical 
examination when the cohort members were aged 45-69 and repeated at two subsequent clinical examinations in 2002/04 and $2007 / 09,{ }^{23}$ providing a follow-up period of 10 years. All participants provided written consent and the University College London ethics committee approved the study.

\section{Measures}

Covariates were drawn from the 1997/99 wave: age, gender, educational attainment (none or lower primary school, lower secondary school, higher secondary school, university, higher university degree), chronic disease up to and including baseline (physician diagnosed cancer, coronary heart disease, stroke excluding transient ischaemic attack, diabetes) and a vocabulary score. Coronary heart disease was ascertained based on clinically verified events, including myocardial infarction and definite angina. Information on stroke events was obtained both from self-reports, and from 1989, hospital episode statistics records. Diabetes was defined as having fasting glucose $\geqslant 7.0 \mathrm{mmol} / \mathrm{l}$ or a $2 \mathrm{~h}$ postload glucose $\geqslant 11.1 \mathrm{mmol} / \mathrm{l}$ using a $75 \mathrm{~g}$ oral glucose tolerance test. ${ }^{24}$ The Mill Hill Vocabulary Test consists of 33 stimulus words ordered by increasing difficulty and has six response choices. ${ }^{25}$

Data on cigarette smoking and alcohol consumption were obtained from questionnaires in 1985/88 (recruitment), 1991/93, 1997/99 (baseline cognitive assessment), 2002/04 and 2007/09. Participants were asked about their alcohol consumption in the past 7 days (measures of spirits, glasses of wine, pints of beer). They were classified as non-drinkers ( 0 units of alcohol per week), moderate drinkers (1-14 units a week for women or 1-21 units per week for men) or heavy drinkers ( $>14$ units per week for women and $>21$ units per week for men). ${ }^{26}$ Smoking status was classified as current smoker, ex-smoker or never smoker.

The cognitive test battery comprised four cognitive tests and was administered at three clinical examinations over 10 years (1997/99, 2002/04 and 2007/09).

(a) The Alice Heim 4-I (AH4-I) is composed of a series of 65 verbal and mathematical reasoning items of increasing difficulty to be completed in $10 \mathrm{~min}^{27}$

(b) Short-term verbal memory was assessed with a 20 -word free recall test. Participants were presented with a list of 20 oneor two-syllable words at $2 \mathrm{~s}$ intervals and then had to recall them in writing in $2 \mathrm{~min}$.

(c) There were two tests of verbal fluency. ${ }^{28}$ Participants were asked to recall in writing as many ' $\mathrm{S}$ ' words (phonemic fluency) and as many animal names as they could (semantic fluency) in $1 \mathrm{~min}$.

The four cognitive tests were combined to create a global cognitive $z$-score (mean 0, s.d.=1), using the mean and standard deviations from $1997 / 99$ for standardisation, providing that participants had completed at least two tests. Previous research has used global scores constructed in this manner to minimise problems due to measurement error on the individual tests. ${ }^{29}$ From 2002/04, the battery additionally included the MiniMental State Examination (MMSE) ${ }^{30}$ used to identify possible cases of cognitive impairment. ${ }^{31}$

\section{Statistical analysis}

We used latent growth curve models ${ }^{32}$ (also known as randomeffects models) to examine both the cross-sectional and longitudinal association between individuals who were smokers ( $v$. never smokers), ex-smokers ( $v$. never smokers), heavy ( $v$. moderate) or abstinent ( $v$. moderate) alcohol users, and their interactions, and the global cognitive score. Latent growth curve models acknowledge that repeated measures on the same individual are correlated, and allow participants with incomplete follow-up data to be included in the analysis. Both the intercept and the slope are fitted as random effects, allowing each to vary between individuals, but without conditioning the slope on the baseline score. ${ }^{33}$ We divided participants' time scores (in years) by 10 so that coefficients describe cognitive decline over 10 years. A model containing the alcohol consumption and smoking status variables (and covariates) and their product terms (alcohol consumption $\times$ smoking status) was compared with a nested model that only contained the exposure variables (and covariates), using a likelihood ratio test (a test of global interaction, also known as the chi-squared difference test) separately for the intercepts and slopes.

Older adults experience faster cognitive decline, ${ }^{3}$ allowing us to compare the effect of being in a particular 'alcohol consumption $\times$ smoking status' group with the effect of being 1 year older, providing information about clinical significance. The two effect sizes were compared using the formula $\left(\mathrm{B}_{\text {group }} / \mathrm{B}_{\text {one year older }}=\right.$ age effect $)$.

The linear dose-response association between alcohol units and cigarettes was evaluated among males who were cigarette smokers and heavy drinkers respectively, given low statistical power among females who were smokers. To normalise the skewed distribution, alcohol units were natural log transformed (constant added) and consumption fitted using log units together with an intercept term indicating alcohol use $v$. non-use. ${ }^{34}$ The number of cigarettes smoked could not be normalised by transformation and was therefore grouped into $1-10,11-20,21+$ cigarettes per day ( $v$. none) to match clear peaks in the distribution at 10 and 20 cigarettes per day.

Several sensitivity analyses were performed. First, we repeated analyses among participants with an MMSE score of 24 or more ${ }^{31}$ in 2002/04 and 2007/09 to ensure that results were not driven by possible cases of cognitive impairment. Second, we additionally adjusted results for the highest Mill Hill Vocabulary Test score obtained, to evaluate the impact of possible reverse causation. ${ }^{35}$ Since vocabulary is resistant to cognitive decline, ${ }^{9}$ it is often used as a measure of premorbid cognitive function. Third, we calculated a cumulative risk score for smoking, alcohol and their interaction from recruitment to baseline (1985/88, 1991/93 and 1997/99); to evaluate whether previous cumulative exposure was also associated with cognitive function and decline. Fourth, we evaluated the impact of behaviour change on results by excluding participants who changed their behaviour after baseline in 1997/ 99 (smokers who had stopped smoking or heavy alcohol drinkers who no longer drank heavily in 2002/04 and 2007/09). Fifth, we repeated the models after excluding participants who were very heavy drinkers ( $>35$ units per week $)^{26}$ and heavy smokers ( $>20$ cigarettes per day) at the same time, to evaluate their impact on results. Sixth, we added a term (male $\times$ smoking status) to the model to capture the previously reported association between current smoking and cognitive decline observed in men only, ${ }^{9}$ to confirm results were consistent. Seventh, we repeated the models on each of the four cognitive tests, to evaluate whether patterns differed for memory compared with tests that involve executive function (reasoning, semantic and phonemic fluency). Eighth, we repeated the analysis on a nested sample of participants with complete data from baseline to follow-up. Similar results among those with complete $v$. missing data would provide evidence against a healthy-survivor effect. Finally, we also compared models including participants reporting no alcohol use in the past 7 days but regular use at other times (occasional drinkers) with those reporting no use at other times (nondrinkers), to evaluate whether heterogeneity in the ' 0 alcohol units per week' group influenced our findings. 


\section{Results}

The analytic sample comprised 6473 participants (4635 men) with data on cigarette smoking, alcohol units, covariates and global cognition for at least one examination. Of the analytic sample, $68.4 \%$ had three waves of cognitive data and $19.3 \%$ had two waves. Compared with the Whitehall II study population at recruitment $(1985 / 88, n=10308)$ those excluded were slightly older (mean $44.8 v .44 .2$ years in 1985-88, $P<0.001$ ), more likely to be female $(41.1 \%$ v. $28.4 \%, P<0.001)$, more likely to smoke $(24.7 \%$ v. $14.8 \%, P<0.001)$ and less likely to drink alcohol heavily (14.6\% v. $16.3 \%, P<0.001)$. Table 1 presents characteristics of the participants included in the analysis, showing that individuals who were current smokers were more likely to drink alcohol heavily.

Growth curve models to estimate the combined effect of alcohol consumption and smoking status at baseline (1997/99) on global cognitive score over follow-up (2002/04 and 2007/09) were fitted with adjustment for age, gender, prevalent chronic disease and educational attainment. These models showed a significant interaction between smoking status and alcohol consumption, both for the intercept (cognitive function at baseline, $\left.\chi^{2}(4)=20.83, P \leqslant 0.001\right)$ and the slope (cognitive decline over 10 years, $\left.\chi^{2}(4)=9.99, P=0.04\right)$.

In order to estimate the combined effect of each alcohol $\times$ smoking status group, the model was re-parameterised and fitted using eight dummy variables that compared each alcohol $\times$ smoking status group with the largest group used as the reference group (never smoker, moderate alcohol drinker). This enabled estimation of the cognitive outcomes in each group in terms of cognition function in 1997/99 (intercept) and cognitive decline during the follow-up (slope). Table 2 shows the estimated mean intercept and slope for each alcohol $\times$ smoking status group (coefficients for the alternative parameterisation are shown in online Table DS1, and for all groups in online Table DS2). Compared with those who were never smokers and consumed a moderate amount of alcohol, participants reporting no alcohol consumption in the previous 7 days generally had worse cognitive function at baseline. Moderate drinkers who were current smokers also had a significantly lower baseline cognitive function. In general, estimated cognitive function at baseline was higher as alcohol consumption increased.

In analysis of cognitive decline (expressed as the change in cognitive function over 10 years), only one group differed significantly from the reference group of never smokers and moderate alcohol users. In individuals who were current smokers and who were also heavy drinkers, cognitive decline was $36 \%$ faster than the reference group. Cognitive decline in this group was equivalent to an age effect of 12 years $(-0.153 /$ $-0.013=12), 2$ years faster than in those who were non-smoking moderate drinkers (an age effect of 2 extra years over 10-year follow-up). Figure 1 shows both the baseline cognitive function (intercept) and the cognitive decline trajectory (slope) for the 'current smoker, heavy drinker' group compared with the total sample.

Among those reporting alcohol consumption, we observed a linear dose-response association between log alcohol units and 10-year cognitive decline among the male smokers group $\left(B_{\text {slope }}=-0.12,95 \% \mathrm{CI}-0.20\right.$ to $\left.-0.04, P=0.004\right)$. Cognitive decline was faster as the number of alcohol units increased (online Fig. DS1).

Among males who were heavy alcohol drinkers, cigarette smoking ( $v$. never smoking) was associated with significantly

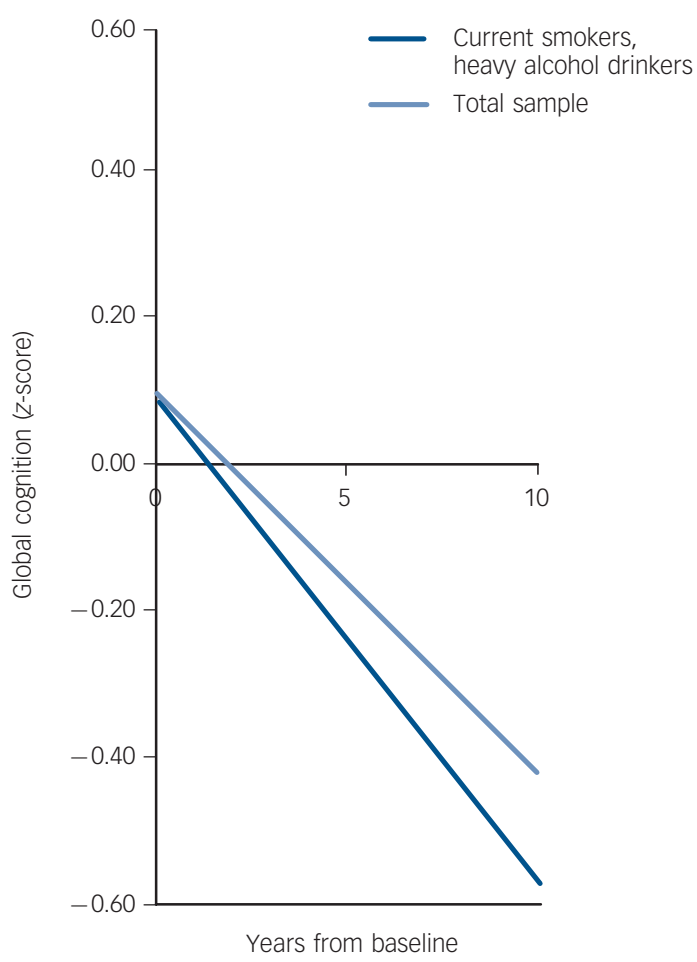

Fig. 1 Cognitive decline in the 'current smoker, heavy alcohol drinker' group compared with the total sample.

Table 1 Characteristics of the study population according to cigarette smoking status and alcohol drinking level (1997/99)

\begin{tabular}{|c|c|c|c|c|c|}
\hline & $\begin{array}{l}\text { Never smoker group } \\
\qquad(n=3192)\end{array}$ & $\begin{array}{l}\text { Ex-smoker group } \\
\qquad(n=2647)\end{array}$ & $\begin{array}{l}\text { Current smoker group } \\
\qquad(n=634)\end{array}$ & $P^{a}$ & $\begin{array}{c}\text { Total } \\
(n=6473)\end{array}$ \\
\hline Age at baseline, years: mean (s.d.) & 55.48 (6.09) & $56.25(5.96)$ & $55.07(5.75)$ & 0.17 & $55.76(6.02)$ \\
\hline Male, $n(\%)^{\mathrm{b}}$ & $2186(68.5)$ & $2033(76.8)$ & $416(65.6)$ & 0.01 & $4635(71.6)$ \\
\hline Chronic disease, $n(\%)^{\mathrm{b}}$ & $672(21.1)$ & $597(22.6)$ & $153(24.1)$ & 0.05 & $1422(22.0)$ \\
\hline \multicolumn{6}{|l|}{ Education, $n(\%)^{\mathrm{b}}$} \\
\hline Lower secondary or lower & $1272(39.9)$ & $1239(46.8)$ & $365(57.6)$ & \multirow{3}{*}{$<0.001$} & $2876(44.4)$ \\
\hline Higher secondary & $812(25.4)$ & $697(26.3)$ & $165(26.0)$ & & $1674(25.9)$ \\
\hline University or higher & $1108(34.7)$ & $711(26.9)$ & $104(16.4)$ & & $1923(29.7)$ \\
\hline \multicolumn{6}{|c|}{ Alcohol drinking status, units per week: $n(\%)^{b}$} \\
\hline 0 & $597(18.7)$ & $283(10.7)$ & $114(18.0)$ & \multirow{3}{*}{$<0.001$} & $994(15.4)$ \\
\hline $1-14$ for women and $1-21$ for men & $2033(63.7)$ & $1567(59.2)$ & $311(49.1)$ & & $3911(60.4)$ \\
\hline$>14$ for women and $>21$ for men & $562(17.6)$ & $797(30.1)$ & 209 (33.0) & & $1568(24.2)$ \\
\hline
\end{tabular}


faster cognitive decline $\left(\mathrm{B}_{\text {slope }}=-0.22,95 \% \mathrm{CI}-0.35\right.$ to -0.10 , $P=0.001$ ), consistent with the results from the interaction models. Among these men there was little evidence for a dose-response association between the number of cigarettes smoked and cognitive decline: $1-10$ cigarettes per day $\left(\mathrm{B}_{\text {slope }}=-0.14,95 \% \mathrm{CI}\right.$ -0.28 to $0.01, P=0.06) ; 11-20$ cigarettes per day $\left(B_{\text {slope }}=-0.32\right.$, $95 \% \mathrm{CI}-0.53$ to $-0.10, P=0.01) ; \geqslant 21$ cigarettes per day $\left(\mathrm{B}_{\text {slope }}=-0.15,95 \% \mathrm{CI}-0.37\right.$ to $0.08, P=0.21$ ) (online Fig. DS2).

Results from sensitivity analyses are summarised in Table 3 These did not influence the conclusions drawn from the main analysis materially. For the 'non-smoker, 0 alcohol units per week' group, effect sizes were similar for non-drinkers and occasional drinkers (17\% v. 19\% faster than the reference group respectively).

\section{Discussion}

This study of over 6000 adults aged 45-69 years at the start of cognitive testing examined cigarette smoking and alcohol consumption as predictors of cognitive decline assessed three times over 10 years. The combined effect of cigarette smoking and heavy alcohol consumption accelerated cognitive decline over the 10 -year follow-up period. Cognitive decline was 36\% faster in those who reported both cigarette smoking and drinking alcohol above the recommended limits at baseline, this effect was equivalent to an age effect of an additional 2 years over 10 -year follow-up. The pattern was strongest for tests requiring executive function; that is reasoning, semantic and phonemic fluency.

\section{Strengths and limitations}

The large sample size, long follow-up period and multiple waves of cognitive assessment strengthen confidence in the results. Several known confounding factors were controlled for in the analysis. Combining four tests into a single measure of global cognition can reduce measurement error. There are some limitations to our study. First, participants reporting 0 alcohol units per week in the past 7 days were a heterogeneous group comprising occasional drinkers, lifetime abstainers, those with existing morbidity (including 'sick quitters') and those not drinking alcohol for other reasons. 'Sick quitters' may account partly for the significantly higher levels of chronic disease observed in those reporting 0 alcohol units per week (online Table DS3). It is also possible that symptoms of prodromal cognitive decline may have motivated participants to stop drinking alcohol. This makes it difficult to determine any protective effect of non-drinking, because this group contains some previously heavy drinkers and a high prevalence of chronic disease. However, effect sizes were similar among occasional and non-drinkers. Second, because all participants were white collar workers, results may not generalise to manual occupations or to the unemployed. However, the cohort covers a wide socioeconomic range, with a tenfold difference in full-time salary between the highest and lowest occupational grade.

\section{Comparison to other studies}

Previous studies evaluating the combined impact of cigarette smoking and alcohol use on risk of cognitive decline or dementia have focused on older adults, ${ }^{2,20,21,35,36}$ often with smaller sample sizes and have tended to be cross-sectional ${ }^{20}$ or case-control studies of Alzheimer's disease, ${ }^{12,21,22}$ few of which have been longitudinal. ${ }^{21,22}$ Previous studies have also suggested that tobacco and alcohol may modify each other's effects on Alzheimer's disease, ${ }^{12,22}$ although these studies did not distinguish moderate from heavy alcohol drinkers. We studied longitudinally the 


\begin{tabular}{|c|c|c|c|c|}
\hline Issue & Procedure & Results & $\begin{array}{l}\text { Effect }^{\mathrm{a}} \\
\%\end{array}$ & Conclusions \\
\hline $\begin{array}{l}\text { Possible cognitive } \\
\text { impairment }\end{array}$ & $\begin{array}{l}\text { Repeat model on those with } \\
\text { MMSE score of } 24 \text { or more in } \\
2002 / 04 \text { and } 2007 / 09\end{array}$ & Unchanged & 36 & $\begin{array}{l}\text { Removal of cognitive impairment cases } \\
\text { does not influence the results }\end{array}$ \\
\hline $\begin{array}{l}\text { Reverse causation (prior } \\
\text { cognitive function may } \\
\text { have led to heavy alcohol } \\
\text { use at baseline) }\end{array}$ & $\begin{array}{l}\text { Additionally adjust for } \\
\text { vocabulary score }\end{array}$ & $\begin{array}{l}\text { Association between heavy } \\
\text { alcohol use and cognitive function } \\
\text { at baseline attenuated by } 40 \% \text {. } \\
\text { Cognitive decline slightly faster }\end{array}$ & 41 & $\begin{array}{l}\text { Reverse causation may contribute to the } \\
\text { association between heavy alcohol use } \\
\text { and cognitive function at baseline, but } \\
\text { does not contribute to the combined } \\
\text { effect of heavy alcohol use and smoking } \\
\text { on cognitive decline }\end{array}$ \\
\hline Cumulated risk & $\begin{array}{l}\text { Repeat using cumulative risk } \\
\text { score from recruitment to } \\
\text { baseline (1985/88, 1991/93, } \\
\text { 1997/99) }\end{array}$ & $\begin{array}{l}\text { Cumulated combined risk score } \\
\text { associated with faster cognitive } \\
\text { decline }\end{array}$ & $N / A^{b}$ & $\begin{array}{l}\text { Cumulative combined exposure increases } \\
\text { cognitive decline }\end{array}$ \\
\hline $\begin{array}{l}\text { Behaviour change during } \\
\text { follow-up }\end{array}$ & $\begin{array}{l}\text { Exclude current smokers who } \\
\text { stopped smoking and heavy } \\
\text { alcohol drinkers who reduced } \\
\text { consumption }\end{array}$ & $\begin{array}{l}\text { Cognitive decline slightly faster in } \\
\text { combined heavy drinker, current } \\
\text { smoker group }\end{array}$ & 37 & $\begin{array}{l}\text { Combined effect is slightly stronger for } \\
\text { participants who continue engaging in } \\
\text { both behaviours over follow-up }\end{array}$ \\
\hline Outliers & $\begin{array}{l}\text { Exclude heavy smokers ( }>20 \\
\text { cigarettes per day) and very } \\
\text { heavy drinkers ( }>35 \text { units per } \\
\text { week) }\end{array}$ & $\begin{array}{l}\text { Cognitive decline only slightly } \\
\text { attenuated in combined heavy } \\
\text { drinker, current smoker group } \\
\text { and still significant }\end{array}$ & 34 & $\begin{array}{l}\text { These participants do not account for } \\
\text { the interaction }\end{array}$ \\
\hline Male smoker effect & $\begin{array}{l}\text { Add interaction between gender } \\
\text { and smoking status }\end{array}$ & $\begin{array}{l}\text { Interaction term not attenuated } \\
\text { and remains significant }\end{array}$ & $N / A^{b}$ & $\begin{array}{l}\text { Male smokers do not account for the } \\
\text { interaction }\end{array}$ \\
\hline Specificity of effects & $\begin{array}{l}\text { Repeat models on executive } \\
\text { function/memory separately }\end{array}$ & $\begin{array}{l}\text { Similar effect size for executive } \\
\text { function, smaller and non-significant } \\
\text { effect for memory }\end{array}$ & $39 / 19$ & $\begin{array}{l}\text { The interaction is apparently specific } \\
\text { to executive function }\end{array}$ \\
\hline $\begin{array}{l}\text { Healthy survivor effects } \\
\text { during follow-up }\end{array}$ & $\begin{array}{l}\text { Repeat results on nested sample } \\
\text { of participants with complete } \\
\text { data during follow-up }\end{array}$ & $\begin{array}{l}\text { Cognitive decline slightly faster in } \\
\text { the combined heavy drinker, } \\
\text { current smoker group }\end{array}$ & 42 & $\begin{array}{l}\text { The combined effect of current smoking } \\
\text { and heavy alcohol drinking on decline } \\
\text { may be underestimated, as a result of } \\
\text { healthy survivor effects from baseline } \\
\text { to end of follow-up }\end{array}$ \\
\hline
\end{tabular}

combined effect of both behaviours from midlife to early old age on both cognitive function and decline.

There is now consistent evidence to suggest that studies based on elderly people have selection bias because of the greater mortality among smokers, producing a selected group of older smokers. ${ }^{37}$ Although our study followed participants from midlife, we found some evidence for a healthy survivor effect over follow-up. It is therefore likely that we underestimated the combined effect of smoking and heavy alcohol drinking on cognitive decline, owing to greater mortality among smokers and heavy alcohol drinkers. The findings presented here extend our previous report that smoking in men is associated with faster cognitive decline over 10 years (online Table DS4). ${ }^{9}$

\section{Meaning of the study}

It is important to know whether the effects of smoking and alcohol use combine to increase risk of cognitive decline in early old age, since this may offer opportunities for prevention. Strategies designed to encourage adults to stop smoking could be implemented sequentially with other behaviour change interventions, such as using smoking cessation to begin discussions about other risky behaviours. Preventable risk factors that co-occur could potentially offer a double dividend, since removal of either risk factor can remove the excess risk associated with the risk factor and the excess risk associated with the interaction. ${ }^{34}$ However, the particularly strong combined effect we demonstrate here should not detract from concerns about the separate impact of unhealthy behaviours, ${ }^{8,13}$ particularly smoking, ${ }^{9}$ but additionally shows the importance of looking at how the effects of behaviours may combine.

Future research should identify reasons why combining these two behaviours accelerates cognitive decline. Studies could look at cumulative damage to aerodigestive or vascular pathways and any subsequent association with cognitive decline. In terms of public health recommendations, guidelines already exist about smoking and drinking alcohol within recommended level ${ }^{26}$ but these could be modified to emphasise excess risk from combined behaviours.

\section{Implications}

From a public health perspective, the increasing burden associated with cognitive ageing could be reduced if lifestyle risk factors can be modified. ${ }^{8}$ We concur with Anttila $e t a l^{38}$ that people should not drink more heavily in the belief that alcohol is a protective factor against cognitive decline. Our findings, assuming the observed associations are causal, show that alcohol use and cigarette smoking do not appear to 'cancel each other out'. ${ }^{22}$ Their combined effect appears to accelerate cognitive decline. Individuals who smoke should stop or cut down, and avoid heavy alcohol drinking, consistent with existing advice. Adults should additionally be advised however, not to combine these two unhealthy behaviours, particularly from midlife onwards. 
Gareth Hagger-Johnson, PhD, Séverine Sabia, PhD, Eric John Brunner, Martin Shipley, PhD, Martin Bobak, PhD, Michael Marmot, MBBS, MPH, PhD, FRCP, FFPHM, FmedSci, Mika Kivimaki, PhD, Department of Epidemiology and Public Health, University College London, UK; Archana Singh-Manoux, PhD, Department of Epidemiology and Public Health, University College London, UK, Centre de Gérontologie, Hôpital Ste Périne and INSERM, U1018, Hôpital Paul Brousse, Paris, France

Correspondence: Gareth Hagger-Johnson, PhD, Department of Epidemiology and Public Health, University College London, London WC1E 6BT, UK. Email: g.hagger-johnson@ucl.ac.uk

First received 26 Oct 2012, final revision 23 Mar 2013, accepted 17 Apr 2013

\section{Funding}

G.H.-J. is supported by a grant from the National Institute on Aging, NIH (R01AG034454 principal investigators: A.S-M. and M.K.) and from the NHS Leeds Flexibility \& Sustainability Fund (principal investigator: Fullard). S.S is supported by a grant from the National Institute on Aging, NIH (R01AG034454, principal investigator: A.S-M. and M.K.). A.S.-M. is supported by a grant from the National Institute on Aging, NIH (R01AG013196; R01AG034454). M.S. is supported by the British Heart Foundation. M.K. is supported by the Medical Researc Council, the National Institutes of Health (R01HL036310; R01AG034454), the Academy of Finland, and by a professorial fellowship from the Economic and Social Research Council (ESRC). The Whitehall II study is also supported by a grant from the British Medical Research Council (K013351) and the British Heart Foundation. Tracing of stroke events was funded by a grant from the Stroke Association (principal investigator: E.J.B).

\section{Acknowledgements}

We thank all of the participating civil service departments and their welfare, personnel, and establishment officers; the British Occupational Health and Safety Agency; the British council of Civil Service Unions; all participating civil servants in the Whitehall II study; and all members of the Whitehall II study team. The Whitehall II study team comprises research scientists, statisticians, study coordinators, nurses, data managers, administrative assistants and data entry staff, who make the study possible.

\section{References}

1 Plassman BL, Williams JJW, Burke JR, Holsinger T, Benjamin S. Systematic review: factors associated with risk for and possible prevention of cognitive decline in later life. Ann Intern Med 2010; 153: 182-93.

2 Steffens D, Otey E, Alexopoulos G, Butters M, Cuthbert B, Ganguli M, et al Perspectives on depression, mild cognitive impairment, and cognitive decline. Arch Gen Psychiatry 2006; 63: 130-8.

3 Singh-Manoux A, Kivimaki M, Glymour M, Elbaz A, Berr C, Ebmeier K, et al. Timing of onset of cognitive decline: results from Whitehall II prospective cohort study. BMJ 2012; 344: d7622.

4 Elias MF, Beiser A, Wolf PA, Au R, White RF, D'Agostino RB. The preclinical phase of Alzheimer disease: a 22-year prospective study of the Framingham Cohort. Arch Neurol 2000; 57: 808-13.

5 Brayne $\mathrm{C}$. The elephant in the room - healthy brains in later life, epidemiology and public health. Nat Rev Neurosci 2007; 8: 233-9.

6 NHS Information Centre. Health Survey for England - 2010: Trend Tables. NHS Information Centre, 2011.

7 Peters R, Poulter R, Warner J, Beckett N, Burch L, Bulpitt C. Smoking, dementia and cognitive decline in the elderly, a systematic review. BMC Geriatrics 2008; 8: 36.

8 Anstey KJ, von Sanden C, Salim A, O'Kearney R. Smoking as a risk factor for dementia and cognitive decline: a meta-analysis of prospective studies. Am Epidemiol 2007; 166: 367-78.

9 Sabia S, Elbaz A, Dugravot A, Head J, Shipley M, Hagger-Johnson G, et al. Impact of smoking on cognitive decline in early old age: the Whitehall II cohort study. Arch Gen Psychiatry 2012; 69: 627-35.

10 Graves AB, van Duijn CM, Chandra V, Fratiglioni L, Heyman A, Jorm AF, et al. Alcohol and tobacco consumption as risk factors for Alzheimer's disease: a collaborative re-analysis of case-control studies. EURODEM Risk Factors Research Group. Int J Epidemiol 1991; 20 (suppl 2): 48-57.

11 Lee PN. Smoking and Alzheimer's disease: a review of the epidemiological evidence. Neuroepidemiology 1994; 13: 131-44.

12 Garcia AM, Ramon-Bou N, Porta M. Isolated and joint effects of tobacco and alcohol consumption on risk of Alzheimer's disease. J Alzheimers Dis 2010; 20: $577-86$.

13 Anstey KJ, Mack HA, Cherbuin N. Alcohol consumption as a risk factor for dementia and cognitive decline: meta-analysis of prospective studies. Am J Geriatr Psychiatry 2009; 17: 542-55.
14 Poortinga W. The prevalence and clustering of four major lifestyle risk factors in an English adult population. Prev Med 2007; 44: 124-8.

15 Hart C, Davey Smith G, Gruer L, Watt G. The combined effect of smoking tobacco and drinking alcohol on cause-specific mortality: a 30 year cohort study. BMC Public Health 2010; 10: 789.

16 Zeka A, Gore R, Kriebel D. Effects of alcohol and tobacco on aerodigestive cancer risks: a meta-regression analysis. Cancer Causes Control 2003; 14 897-906.

17 Schinka J, Vanderploeg R, Rogish M, Graves AB, Mortimer J, Ordoric PI. Effects of the use of alcohol and cigarettes on cognition in elderly adults. J Int Neuropsychol Soc 2002; 8: 811-8.

18 Schinka JA, Belanger $\mathrm{H}$, Mortimer JA, Graves AB. Effects of the use of alcohol and cigarettes on cognition in elderly African American adults. $J$ Int Neuropsychol Soc 2003; 9: 690-7.

19 Herbert LE, Scherr PA, Beckett LA, Albert MS, Rosner B, Taylor JO, et al. Relation of smoking and low-to-moderate alcohol consumption to change in cognitive function: a longitudinal study in a defined community of older persons. Am J Epidemiol 1993; 137: 881-91.

20 Ngandu T, Helkala E-L, Soininen H, Winblad B, Tuomilehto J, Nissinen A, et al. Alcohol drinking and cognitive functions: findings from the Cardiovascular Risk Factors Aging and Dementia (CAIDE) Study. Dement Geriatr Cogn Disord 2007; 23: 140-9.

21 Leibovici D, Ritchie K, Ledésert B, Touchon J. The effects of wine and tobacco consumption on cognitive performance in the elderly: a longitudinal study of relative risk. Int J Epidemiol 1999; 28: 77-81.

22 Tyas SL, Koval JJ, Pederson LL. Does an interaction between smoking and drinking influence the risk of Alzheimer's disease? Results from three Canadian data sets. Stat Med 2000; 19: 1685-96.

23 Marmot M, Brunner E. Cohort profile: the Whitehall II study. Int J Epidemiol 2005; 34: 251-6.

24 Alberti KG, Zimmet PZ. Definition, diagnosis and classification of diabetes mellitus and its complications. Part 1: diagnosis and classification of diabetes mellitus provisional report of a WHO consultation. Diabet Med 1998; 15: 539-53.

25 Raven JC. Guide to using the Mill Hill Vocabulary Test with Progressive Matrices. HK Lewis, 1965.

26 Royal Colleges of Physicians, Royal College of Psychiatrists and Royal College of General Practitioners. Alcohol and the Heart in Perspective: Sensible Limits Reaffirmed. Royal Colleges of Physicians, Royal College of Psychiatrists and Royal College of General Practitioners, 1995.

27 Heim AW. AH4 Group Test of General Intelligence. nferNelson, 1970

28 Borkowski JG BA, Spreen O. Word fluency and brain damage. Neuropsychologia 1967; 5: 135-40.

29 Wilson RS, Leurgans SE, Boyle PA, Schneider JA, Bennett DA. Neurodegenerative basis of age-related cognitive decline. Neurology 2010; 75: $1070-8$.

30 Folstein MF, Folstein SE, McHugh PR. "Mini-mental state". A practical method for grading the cognitive state of patients for the clinician. J Psychiatr Res 1975; 12: 189-98.

31 Anstey K, Burns R, Birrell C, Steel D, Kiely K, Luszcz M. Estimates of probable dementia prevalence from population-based surveys compared with dementia prevalence estimates based on meta-analyses. BMC Neurology 2010; 10: 62 .

32 Bollen KA. Latent Curve Models: A Structural Equation Perspective. John Wiley, 2006

33 Glymour MM, Weuve J, Berkman LF, Kawachi I, Robins JM. When is baseline adjustment useful in analyses of change? An example with education and cognitive change. Am J Epidemiol 2005; 162: 267-78.

34 Kirkwood B, Sterne J. Essentials of Medical Statistics. Blackwell Publishing, 2003.

35 Corley J, Jia XL, Brett CE, Gow AJ, Starr JM, Kyle JAM, et al. Alcohol intake and cognitive abilities in old age: the Lothian Birth Cohort 1936 study. Neuropsychology 2011; 25: 166-75.

36 Tyas SL. Alcohol use and the risk of developing Alzheimer's disease. Alcohol Res Health 2001; 25: 299-306.

37 Sabia S, Marmot M, Dufouil C, Singh-Manoux A. Smoking history and cognitive function in middle age from the Whitehall II study. Arch Intern Med 2008; 168: 1165-73.

38 Anttila T, Helkala E-L, Viitanen M, Ingemar K, Fratiglioni L, Winblad B, et al Alcohol drinking in middle age and subsequent risk of mild cognitive impairment and dementia in old age: a prospective population based study BMJ 2004; 329: 539 . 